\title{
Students' perspectives on the design and implementation of a blended synchronous learning environment
}

\author{
Qiyun Wang \\ National Institute of Education, Nanyang Technological University, Singapore \\ Changqin Huang \\ School of Information Technology in Education, South China Normal University, China \\ Choon Lang Quek \\ National Institute of Education, Nanyang Technological University, Singapore
}

This study investigated a blended synchronous learning environment (BSLE), which was designed for a group of master's students taking a course at a teacher education institute. The BSLE was created for the majority of the students to attend the course face-to-face and at the same time allowed the rest to join the identical sessions using videoconferencing from different locations. The purpose of the study was to find out what learning experiences and perceptions the students had with regard to the design and implementation of the BSLE. Results show that the BSLE could extend certain features of the face-to-face classroom instruction to the online students and the students liked the flexibility and convenience of attending lessons via the twoway videoconferencing at remote sites. This study further identified that smooth communication between online students and the instructor and between the online students and classroom students, the engagement of the online students and the redesign of certain instructional activities, balanced attention from the instructor to the classroom students as well as the online students and the quality of the audio were crucial for the environment to be effective.

\section{Introduction}

Classroom instruction has unique features such as rich social cues, immediate feedback and socialisation, which often result in students' clear preference for face-to-face (F2F) interactions whenever conditions allow (Altiner, 2015; Stewart, Harlow, \& DeBacco, 2011). Despite this, students are not always able to enjoy such opportunities, for instance, at times of major events like a worldwide pandemic or a catastrophe that causes schools to shut down and classes to cease functioning (White, Ramirez, Smith, \& Plonowski, 2010). To cite a real example, Singapore has been affected by severe smoke haze due to forest fire from the region in recent years. Schools were once closed for a day in 2015 and many students fell sick during the period and were not able to go to school. This situation may happen again and even more frequently in the future. In addition, primary or secondary school students may not be able to come to class due to illness or physical conditions (Martin, 2005), and adult learners may have to be absent from regular classes because of social or family commitments (Gillies, 2008). To allow the absent students to continue participating, institutions often simply upload learning materials to learning management systems and let the students download and learn asynchronously by themselves. This method may work well for a short duration but tends to be less effective if the situation persists (Kear, Chetwynd, Williams, \& Donelan, 2012; Warden, Stanworth, Ren, \& Warden, 2013). It would be better if students could find a way to enjoy the convenience of online learning while they are absent and at the same time experience the benefits of real-time F2F instruction. How to create such an environment so that online learning incorporates certain features of the F2F classroom becomes imperative. This study proposed creating a blended synchronous learning environment (BSLE) to address the above problem. In this paper, a BSLE is defined as a technology-supported learning setting where online students and classroom students can participate in identical class activities in real time. The purpose of the paper is to describe the design and implementation of the learning environment and report on students' learning experiences and perceptions. 


\section{Review of the relevant literature}

The advancement of computer-mediated communication technologies has made the extension of the classroom to online students increasingly affordable and feasible (Wang \& Wiesemes, 2012). Learning in such an environment is often called blended synchronous learning (Bower, Dalgarno, Kennedy, Lee, \& Kenney, 2015; Hastie, Hung, Chen, \& Kinshuk, 2010; Szeto, 2015), synchronous blended or hybrid learning (Cain \& Henriksen 2013; Okita, 2013); multi-access learning (Irvine, Code, \& Richards, 2013) or synchronous learning in distributed environments (Warden et al., 2013). Blended synchronous learning is adopted in this paper as an umbrella term to refer to the instructional method that supports teaching and learning simultaneously for both classroom students and online students via computer-mediated communication technologies. By following the blended synchronous learning approach, on-campus students attend F2F instruction in the physical classroom as usual and the students who are absent from the class participate in the identical instructional activities via two-way videoconferencing in real time.

Research often emphasises the use of asynchronous learning tools such as a learning management system to support students' online learning (Warden et al., 2013). In recent years, increasing attention has been drawn to the design of a BSLE to support both classroom students and online students simultaneously, and this is reflected in a number of recently published studies. For instance, Bower et al. $(2014,2015)$ conducted a study on seven cases of using the blended synchronous learning approach in Australia. In each case, a group of students attended classroom teaching conducted by an instructor, while the other group attended the same classroom learning at a remote site using a web conferencing tool. Szeto and Cheng (2016) carried out a similar study in Hong Kong, where 28 students were divided into F2F and online groups. The teacher conducted lessons with the F2F group, and the other group took part in the identical instructional process via videoconferencing at a separate learning centre. Anastasiades et al. (2010) piloted a study in Greece with two elementary schools connected via interactive videoconferencing. The students worked on collaborative activities, and both intergroup (from two schools) and intragroup (from the same school) were involved. It is worth noting that these studies were all carried out with students at two fixed sites only (i.e., a local classroom and a remote learning centre), and few existing studies have explored how to engage online students situated at multiple sites. Learning at multiple sites inevitably presents varied learning experiences and challenges for online students. For instance, they may encounter technical difficulties due to the absence of a teaching or technical assistant. Also, there is a lack of classroom atmosphere compared to studying at a learning centre, and as a result the sense of isolation may be increased.

There are a limited number of studies involving online students studying at multiple places. However, attendance by individual students is often fixed (either online or in the classroom), and the students do not change from one option to the other. For instance, in the study conducted by Irvine et al. (2013), nine on-campus students took a course in a classroom while 17 other students joined the course online via webcams. In another study (Cunningham, 2014), 12 on-campus students and four online students took part in the same classroom learning activities in real time. Both studies were implemented in such a way so that students attended synchronous lessons in one way only (F2F or online) and they lacked the full experience of attending courses in F2F and online forms.

In this study, the majority of students attended F2F sessions in the classroom while the rest joined the sessions via videoconferencing simultaneously but from different locations, as illustrated in Figure 1. All students took part in one or two videoconferencing sessions online and other sessions in the classroom. Furthermore, all of them experienced both F2F and online participation via simultaneous videoconferencing in the course. As an exploratory study, the purpose of this research was to investigate the students' experiences and perceptions of the design and implementation of the BSLE. The research questions were:

(1) What are the learning experiences of the students when they are participating in the BSLE?

(2) What are their perceptions of the blended synchronous learning approach? 


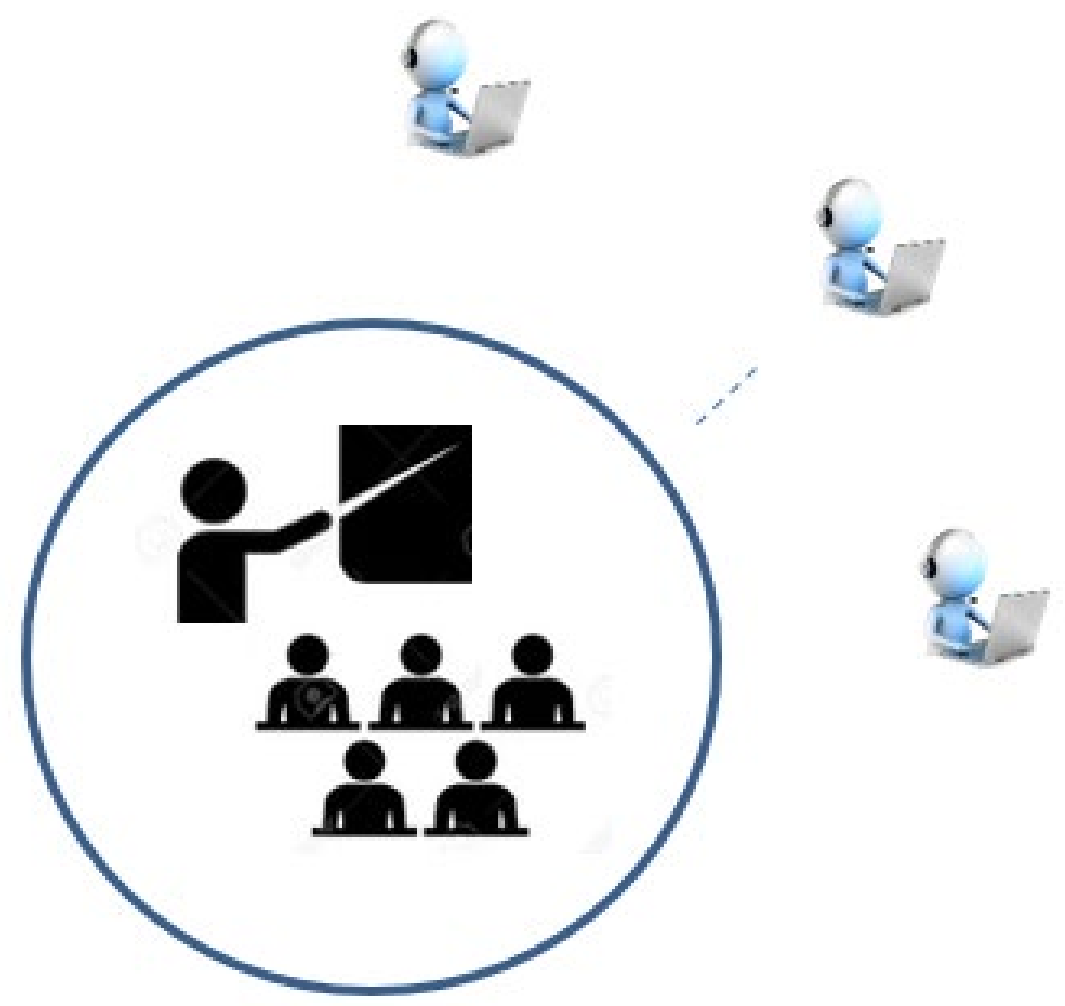

Figure 1. The blended synchronous learning layout

\section{Research design}

\section{The course}

The BSLE was established for a group of master's students who were taking an elective course at a teacher education institute in 2016. A total of 24 students (6 males and 18 females) were enrolled in the course in the semester. Their ages ranged from 25 to 45 years old, and more than $80 \%$ of the students were married with young children. They were all full-time school teachers, and able to attend the course only in the evenings.

The course ran once a week from 6pm to 9pm and lasted for 13 weeks. Each session involved both theory and practice. The theory was delivered via presentation slides, and the practice included hands-on activities and group collaboration. This course has been offered for more than ten years. It is often a challenge for the students to take the course (and other courses as well) in the evenings as they have full-time jobs and families to take care of. To explore the feasibility of allowing certain students to study at home and delivering the same instruction to both F2F and online students simultaneously, four sessions in the course were converted into the blended synchronous learning mode by using videoconferencing in the present study. These sessions were not run continuously but interposed by one to three F2F lessons so that there was enough time for the instructor to reflect and improve on the design and implementation. In each session, about six to eight students joined the classroom instruction via videoconferencing at their preferred sites, such as at home or the office, and the rest remained in the classroom. In the end, all except one student who did not want any videoconferencing sessions attended at least one blended synchronous learning lesson. Figure 2 displays the learning environment and the streaming videos and screens that the students observed. 


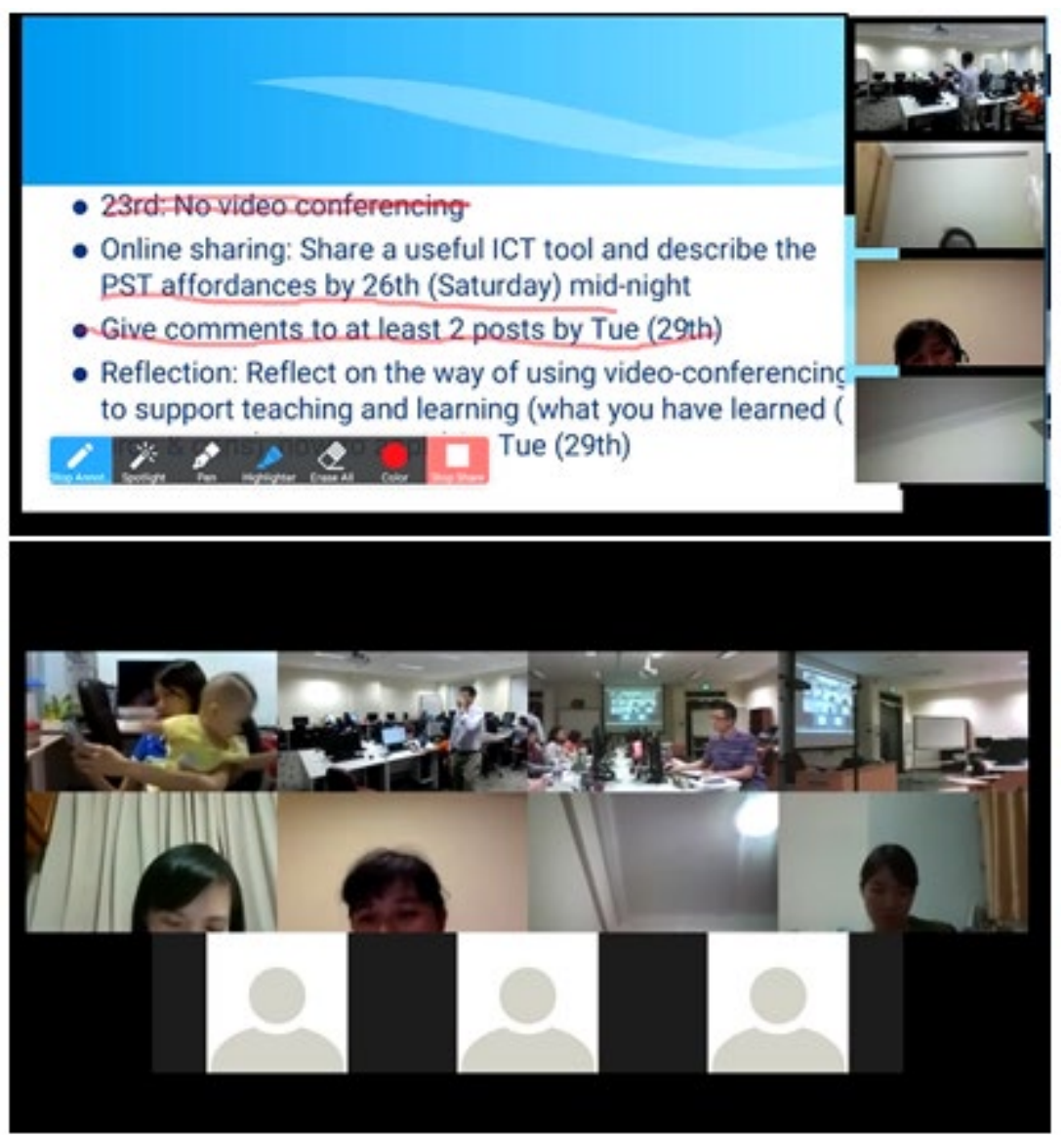

Figure 2. BSLE and screens

\section{The tool}

The tool chosen for the two-way videoconferencing was Zoom (http://www.zoom.us). A striking feature of the tool is that its free version can support up to 50 users online at the same time. However, the free version has a limitation in that each videoconferencing session can last up to a maximum of 40 minutes only. A professional version was hence bought and adopted in this course. Another useful feature of the tool is that it enables users to share computer screens and conduct text chats. In order for the students to easily use the tool, its basic features were demonstrated in the F2F lesson prior to the first blended synchronous learning session. All students downloaded the tool and installed it on their computers in the classroom, and they were given about half an hour to explore the tool. Some students also took the liberty of installing the software on their mobile devices. There were no critical technical problems encountered during the exploration period. To allow the students to opt for their preferred timeslots for videoconferencing, an online spreadsheet with available dates for the conferencing sessions was created for them to fill in. As videoconferencing required a camera and a microphone, the students were also reminded to have these items ready before joining the first session.

\section{Technical strategies}

The technical strategies for implementing the BSLE varied slightly across the four sessions due to the adjustments needed for improvement, as shown in Table 1. In the first session, only one camera was installed in the classroom, and it focused mainly on the instructor. It was later observed that the online students could not see their classmates most of the time, and the classroom atmosphere was compromised. One more camera was added in the second session to give the online students a panoramic view of the classroom. Similarly, only one wireless microphone was installed and used by the instructor in the first two sessions. But feedback from 
the online students indicated that they could not hear their classmates clearly as the microphone was attached to the instructor and could not clearly pick up the voice of the classroom students. From the third session onwards, one more wireless microphone was added to the classroom to capture the students' voices. In addition, a projector was used in the first session to show the slide and streaming videos. However, it was observed that parts of the slides were blocked by the streaming videos, as displayed in the first screenshot of Figure 2 . The slides were covered extensively if the number of videos increased. Another projector was hence added in the second session to solely display the streaming videos. But in the end, it was observed that only four streaming videos could be shown simultaneously and the rest could be displayed by scrolling up or down. Therefore, it became unnecessary to have a second projector. From the third session onwards, one projector remained in the classroom, and the instructor adjusted the layout of the slides to prevent the streaming videos from blocking important information.

Table 1

Strategies used in the blended synchronous learning sessions

\begin{tabular}{|c|c|c|c|c|}
\hline & Session 1 & Session 2 & Session 3 & Session 4 \\
\hline Video & $\begin{array}{l}1 \text { camera: focusing } \\
\text { on the instructor } \\
\text { only }\end{array}$ & $\begin{array}{l}2 \text { cameras: one } \\
\text { focusing on the } \\
\text { instructor and the } \\
\text { other on the whole } \\
\text { class }\end{array}$ & - & - \\
\hline Audio & $\begin{array}{l}1 \text { wireless } \\
\text { microphone } \\
\text { attached to the } \\
\text { instructor }\end{array}$ & - & $\begin{array}{l}2 \text { microphones: one } \\
\text { with the instructor } \\
\text { and the other for } \\
\text { students to talk into }\end{array}$ & - \\
\hline Projector & $\begin{array}{l}1 \text { projector: } \\
\text { showing the shared } \\
\text { screen and } \\
\text { streaming videos }\end{array}$ & $\begin{array}{l}2 \text { projectors: one } \\
\text { showing the shared } \\
\text { screen and the other } \\
\text { showing the videos }\end{array}$ & $\begin{array}{l}\text { Change back to } 1 \\
\text { projector only }\end{array}$ & - \\
\hline Slide & $\begin{array}{l}\text { Using a remote } \\
\text { clicker to turn slides } \\
\text { and using the laser } \\
\text { to draw students' } \\
\text { attention }\end{array}$ & - & $\begin{array}{l}\text { Using a wireless } \\
\text { mouse to show the } \\
\text { movement of the } \\
\text { cursor }\end{array}$ & $\begin{array}{l}\text { Using a mobile } \\
\text { device to turn slides } \\
\text { and highlight } \\
\text { important } \\
\text { information }\end{array}$ \\
\hline Preparation & & & $\begin{array}{l}\text { Online students and } \\
\text { the instructor } \\
\text { joining the } \\
\text { environment } 10 \\
\text { minutes before the } \\
\text { lesson starts }\end{array}$ & \\
\hline Attention & $\begin{array}{l}\text { Paying special } \\
\text { attention to online } \\
\text { students }\end{array}$ & - & - & - \\
\hline Partnership & & $\begin{array}{l}\text { Every online } \\
\text { student having a } \\
\text { partner in the } \\
\text { classroom }\end{array}$ & - & - \\
\hline Collaboration & & & Intergroup activities & - \\
\hline
\end{tabular}

Note: - indicates session remained unchanged

Another strategy was to use a mobile device to present and share the slides so that important information could be highlighted and annotated on the screen for the online students to easily see, as shown on the first screenshot of Figure 2. This strategy was adopted after realising that the online students had difficulties seeing the trace of the laser pen on the projected screen via the camera. Using a wireless mouse to highlight important information 
in the third session was unsuccessful as it was not convenient and natural for the instructor to hold a mouse when he was walking around. In comparison, using a mobile device such as a smart phone or an iPad to advance slides and highlight key information was more convenient and practical. Another strategy used was to having the online students join the videoconferencing room ten minutes before the lesson started so that potential technical problems could be detected and solved earlier. This strategy was brought into the course from the third session after the online students encountered a serious technical problem in the second session which caused the lesson to delay about 15 minutes.

\section{Instructional strategies}

To a great extent, the instructor continued with the instructional strategies used in previous semesters. Both presentations and hands-on activities were kept, and group collaboration on learning tasks were also retained. Nevertheless, because of the blended synchronous nature of the sessions, additional instructional strategies were also explored. One strategy was to pay special attention to the online students. Obviously, during a presentation, the instructor needed to address not only the F2F students but also the online students. He had to monitor the participation and engagement of the online students by asking them questions. By doing this, he could determine if they understood the topic and were following the instructional process closely.

Another instructional strategy used was a learning partnership. In order for the online students to easily follow what was happening in the classroom and notify the instructor promptly of any questions they had, they were advised to choose a peer in the classroom as a partner from the second session. This strategy was implemented because the instructor had difficulty reading all the text chat messages sent by the online students during the class presentation, and many questions remained unanswered. By using the partnership strategy, the questions posted by the online students could be promptly captured and conveyed to the instructor by their classroom partners.

In addition, intergroup collaboration was also implemented. In the last two blended synchronous learning sessions, the students were involved in group activities with members from both the classroom and from the remote sites. In order for the online students to easily participate in the group activities with the students in the classroom, each group in the classroom was provided with a video camera. The students were also encouraged to use other technological tools to support their communication and interaction if needed.

\section{Instruments and data analysis}

This study adopted a qualitative research approach. Unlike a quantitative research study, which often involves an experimental group and a control group for the purpose of comparing learning outcomes, this study focused on identifying students' perceptions and experiences of the design and implementation of the learning environment. Therefore, the following instruments were used for data collection:

\section{Lesson observation}

The instructor (who was also the principal investigator (PI) of the project) conducted the sessions and took note of what was happening in each session. Also, a research assistant was in the classroom to help observe the problems and difficulties the students encountered and any questions they had. After each blended synchronous learning session, the instructor and the research assistant shared and discussed their observation notes and came up with ideas for improving the following session.

\section{Reflections}

The students wrote two reflections: the first reflection was written shortly after taking part in a blended synchronous session via videoconferencing. The instructor sent an email to the online students asking for their feedback on their perceived benefits, challenges and suggestions for improvement. This reflection was not compulsory or graded. About $80 \%$ of students sent reflections. The instructor and a co-PI read the reflections, highlighted key learning experiences and discussed the critical issues mentioned. Furthermore, they gave special attention to the challenges the online students faced and the suggestions they proposed. This together with the above lesson observation notes resulted in revisions for subsequent sessions. 
The second reflection was written after all the blended synchronous learning sessions had been completed. The students were required to write a reflection on their experiences and perceptions of all the sessions. This was done in lieu of a compulsory assignment carrying $10 \%$ of the final marks, and students were given a week to complete it. Similar to the analysis of the above reflection, the instructor and the co-PI read each reflection individually and highlighted typical sentences and paragraphs. Meanwhile, they noted important points with regard to learning experiences, perceived differences and attitudes towards the blended synchronous learning approach and compared and added to their compiled lists respectively by following the constant comparative method (Strauss \& Corbin, 1990). After reading through and analysing all the reflections, the two investigators compared the compiled lists in a F2F meeting. They went through the items and grouped relevant ones into a common theme. They managed to reach a consensus on all the common themes after the meeting. The next section reports on the common themes of the students' learning experiences and perceptions generated from the reflections and supported by the findings from the lesson observations.

\section{Results}

\section{Learning experiences}

The learning experiences were categorised into the following common themes: participation, interaction and technology. Representative excerpts from the students' reflections are quoted to support each theme.

\section{Participation}

a) Flexibility

The students liked the flexibility of blended synchronous learning as it provided additional chances for them to participate in the lessons when they could not join the classroom instruction. For instance, a student wrote in her reflection:

I really like the flexibility of this course. ... My daughter was down with HFMD on the day of the lesson. Even though it was not my video conferencing session, I was able to attend lesson because of the availability of such technology. Otherwise, I would have to miss the lesson for the week.

Nevertheless, it was observed that the participation of the online students in the BSLE was rather low. They occasionally shut down their webcams and did not answer when they were called upon. It is most likely that they left their computers and did not concentrate on the presentation or class activities. In addition, the online students seemed to have difficulties in seeing certain class activities via the classroom cameras. For instance, when the students were looking at how a printed image became interactive when it was viewed on a mobile phone, the online students could not see it clearly even though a classroom camera was focused on the mobile phone screen. This observation was also echoed by a student in her reflection:

I could not see the Augmented Reality demonstration activity from the class video recorder. Fortunately for me, my class-partner took the initiative to video record that segment of the lesson and sent the short videos to me via whatsapp. That was very useful to have a good understanding of what was going on during that time.

\section{b) Partnership}

The students frequently commented on the learning partnership strategy used. They felt it helped them to follow what was happening in the classroom so that they could easily participate in the learning activities:

I thought having a partner was useful as the partner can be the 'spokesperson' for the one at home. For example, $\mathrm{Z}$ found the sound had echo, so I could convey his problem to you [the instructor]. 
He also could not hear you properly so I helped by explaining the main points to him when we met for another class the following day.

However, they also reported some limitations with the partnership strategy. Two students indicated that there was a time delay between the time they posted the questions and the time the partners responded. This is because the partners did not check the text chat promptly and regularly. On the other hand, a classroom partner complained that she could not concentrate on the instructor's presentation because she had to pay attention to her online partner's requests. The following representative quotes from two students shed light on this:

Having a partner in class helps to a certain extent. However, the partner cannot always be checking the chat so [I] had to go through other friends in class who could help me clarify questions.

As a classroom participant, I felt that I could not fully focus on the lesson when I was a partner to an online participant. This is because I have to check the chat messages often in case the online partner has any questions or comments for the lecturer.

In addition, three students suggested that having a separate helper such as a teaching assistant rather than a partner would be more helpful for monitoring the text chat and notifying the instructor. This would enable the questions posted by the online students to be answered promptly and it would also reduce the stress of the classroom partners so that they could concentrated on class activities.

\section{Interaction}

a) Comfort

It was observed that the students were more comfortable when they were taking the course online than in the classroom. They would usually eat or drink during the videoconferencing sessions. A woman taking the course from home even had a baby sitting on her lap (refer to the second screenshot of Figure 2). The students felt that the BSLE provided a friendly and convenient learning environment which enabled online students to ask questions and communicate with classmates. A student wrote in her reflection:

I felt safe and comfortable to share my opinions about an issue or to ask questions to the instructor during video conferencing ... My classmates and I often used the chatroom to raise initial concerns or questions before voicing them aloud in the main conferencing room.

\section{b) Challenges}

Nevertheless, some challenges regarding interaction were also observed. For instance, the interaction between the online students and the classroom students was a problem. The online students could see what was happening in the classroom; they could also directly communicate with the instructor verbally. The instructor could also address their questions promptly, and the online students were able to hear the instructor's voice clearly. Nevertheless, the online students had difficulties in communicating with the classroom students who were not online or had no microphones. Even though a separate mobile microphone was prepared for the classroom students to use from the third session, it seemed that the classroom students had not developed the habit of picking up a microphone and talking into it. As a result, the online students could not hear the classroom students clearly. In addition, some other concerns were also raised. For instance, the chat text sometimes scrolled too fast for them to keep up; the instructor did not check the chat box frequently enough, and hence many questions remained unanswered; the online students encountered difficulties in finding a proper time to ask the instructor questions as eye contact was missing; in spite of the challenge in communicating with group members, they managed to overcome the difficulty and gradually started to collaborate:

Whatever discussion they [the group members in the classroom] had, one of them had to manually type to inform me which became too tedious. At times, I didn't know what they were talking about since the only way of communication was through typing using the chat function. 


\section{Technology}

There were no critical technical difficulties observed or reported in the blended synchronous learning sessions, and it seemed that all online students could easily join the sessions via videoconferencing. Also, the quality of the videos was generally acceptable, with no students complaining about the quality. Nevertheless, the quality of the audio seemed to be a cause for concern. For instance, a student in the second session complained that the audio was unclear and that there was a strong echo in the transmitted audio. After careful checking, it was found that the echo was caused by the newly added video camera which had a built-in microphone. As a result, the voice of the teacher was being transmitted by two microphones, which caused the echo to occur. In addition, some students forgot to turn their microphones off after speaking. Subsequently, the level of noise increased, which also affected the clarity of the audio. The following quote from a student mentions this issue:

During the 3hr video conferencing, I was rather distracted by the noise from other participants' background e.g. children jumping around and/making loud noises. Maybe 'the instructor] can gently remind participants of the issue so that the others are not distracted.

\section{Perceptions}

The perceptions were categorised into the following themes: perceived differences between joining the course in the classroom and taking the course via videoconferencing and students' attitudes towards the blended synchronous learning approach.

\section{Perceived differences}

a) Flexibility

An obvious difference perceived with joining the BSLE via videoconferencing was that it was more flexible than attending F2F lessons because the online students could attend the lessons anywhere using any device (laptops or mobile phones). Also, such a mode of learning allowed the adult learners to multitask:

There was a lot of flexibility when you attend the video conference. Although you are there listening to the lecture, you can actually eat your dinner too! Something which you can't really do in the actual class ...

The students also confirmed that attending the blended synchronous learning sessions at home was more safe and comfortable. The physical home environment allowed them to eat, drink or do housekeeping while the virtual environment supported by videoconferencing provided them an equally comfortable space to interact with the instructor and classmates. This can be seen from the following student's remark:

We can reaffirm our understanding with classmates by providing feedback and opinions via the chat feature. As it also allows for communication to be done privately with any particular classmate, it exudes a safe and non-threatening form of learning environments for introverted students.

b) Equality

Despite the above, it seemed that the students' interactions and experiences in the BSLE were weaker than those in the classroom, and the BSLE could not replace the physical classroom. This is shared in a student's reflection:

No matter how good the technology is, it will never be as good as physically being in the same room. People miss out the visual clues provided by other people's body language, for example, which can sometimes be more revealing than what they are actually saying.

In addition, research shows that the BSLE may have an inherent issue, which is that it could negatively affect the learning experience of the classroom students due to the fact that the instructor might spend more time troubleshooting technical problems for the online students, resulting in paying less attention to the classroom students (Szeto, 2015). Gratifyingly, this was not an issue in the present study, and it was not mentioned in the 
students' reflections. Encouragingly, the students commonly mentioned that they were engaged in the lesson activities as much as in the classroom.

\section{Attitudes}

The students were very positive towards the blended synchronous learning approach. Five students expressed a hope for more courses to be conducted in the same way, and two students even indicated that they would conduct lessons in a similar way in the future. The following quote illustrates a student's preference for the blended synchronous learning approach:

Even though there were some initial uncertainties and technical glitches, I appreciate the positive spirit that [the instructor] has shown throughout the module. Please inform me of such similar modules in future because I would be very interested in joining the class before I graduate.

\section{Discussion}

The purpose of this study was to create a BSLE for online students and classroom students to receive identical instruction in real time and to investigate the students' experiences and perceptions of the design and implementation of the environment. In this section, key findings are summarised and discussed and directions for future research are proposed.

\section{Benefits}

This study demonstrated that blended synchronous learning is a practical approach to extending classroom instruction to the online students who could not attend F2F lessons in a physical classroom. By incorporating two-way videoconferencing into the learning environment, the online students were able to receive classroom instruction in real time at sites convenient to them and interact with their classroom peers. This resulted in the following benefits, which have been reported in other literature: saving travel time and having a comfortable environment for online learners (Gillies, 2008); establishing teacher presence for online students (Rehn, Maor, \& McConney, 2016); offering equivalent learning experiences as those of the F2F classroom (Bower et al., 2015); and classroom students and online students being able to exchange opinions and learn from each other (Anastasiades et al., 2010).

\section{Interaction}

To enable smooth interaction between the online students and the instructor and between the online students and the classroom students, the partnership strategy was implemented in the learning environment. This study found that the partnership strategy was helpful to a certain extent but it was a double-edged sword. On the one hand, it enabled classroom students to help monitor the problems experienced by the online students and notify the instructor promptly, but on the other hand, due to the need to constantly interact with their online counterparts, the classroom partners could be easily distracted, hence affecting their engagement in the class activity. Stewart et al. (2011) reported similar findings. They pointed out that local students in the classroom could help to host and facilitate online students' participation and interaction but they did not mention the downside of the strategy. Hopefully, alternative strategies such as directing communication to one particular mode such as audio or text only (Bower et al., 2015) or using a teaching assistant to monitor the text chat and answer simple questions (White et al., 2010) could work better; and these could be explored in future studies. 


\section{Student engagement and redesign of instructional activities}

Although blended synchronous learning can provide a safe and comfortable environment for online students to communicate and interact with their classroom counterparts as well as with their instructor, there is still a need to understand how it can better involve and engage online students in instructional activities. Being present in an online environment does not mean that a student is actively engaged in the learning process. For example, in this study, the online students intentionally turned off their streaming videos to avoid being observed, which indicates that they might have become bored and most likely walked away from their computers. Similar phenomena were also observed in other studies (e.g., Cunningham, 2014; Gillies, 2008; Karal, Çebi, \& Turgut, 2011). Also, online students initially encountered difficulties in participating in group activities and seeing live demonstrations conducted by the instructor, due to the cameras not being able to capture the full view of the event. This finding is in agreement with the suggestion that the instructor must make necessary accommodations in instructional activities and cannot assume that pedagogical practices used in the conventional classroom will be successful in the new setting (Stewart et al., 2011). Future research could explore how to better design instructional activities so that online students and class students can participate equally in class activities and hence have equivalent learning experiences.

\section{Balanced attention to F2F and online students}

Research cautions that classroom students may feel neglected as the instructor is inclined to spend more time presenting and explaining learning content to online students (Szeto, 2015). In this study, the instructor spent much time in handling the technical issues encountered by the online students. In addition, a student in the study reported that being a classroom partner to her online classmate caused her to lose concentration in the lesson because she had to attend to her partner's requests. Such a concern is also reported in other studies (e.g., Bower et al., 2015; Szeto, 2015). These findings suggest that blended synchronous environments require the instructor to be pedagogically and technologically savvy in managing the hybrid instructional process of delivering simultaneously to both F2F and online students via technology as well as being able to provide equal attention to local and remote students.

\section{Audio}

Audio seems to be a critical factor for blended synchronous learning to succeed. In this study, the online students frequently complained about problems with audio communication, including interruptions or delays in audio transmission, high levels of background noise and echoes. The problems with audio are commonly reported in other studies as well, such as Bower et al. (2015), Gillies (2008), and Kear et al. (2012). They support the notion that the quality of audio in a BSLE must be assured for smooth communication and effective teaching and learning to take place, as interference from audio from different sources can result in poor clarity. From this perspective, the quality of audio is even more crucial than that of video because people can simply close their eyes or ignore a video clip if its quality is low, but they cannot block their ears or skip an audio signal.

\section{Limitations and future study}

This study had a few limitations. First of all, most participants attended blended synchronous learning via videoconferencing once or twice only. As a result, their experiences and perceptions might not be accurate or representative. For instance, the online students in this study did not feel isolated; but they might do so after attending more online sessions, as reported in literature (e.g., Karal et al., 2011). Future research could validate this finding with students participating in more blended synchronous learning sessions via videoconferencing.

The second limitation is that this BSLE supported by videoconferencing lacks provision for online students to be fully immersed in the environment. The online students could only see what the cameras captured, but could not experience the sensation of being in a 3D reality (Anastasiades et al., 2010). The experience of observing streaming videos on screen is very different from being involved in an authentic environment. How to better integrate a virtual learning environment into the classroom environment such as creating a 3D immersive learning environments could be further explored in the future. 


\section{Conclusion}

This study confirms that creating a BSLE using videoconferencing can provide an opportunity for online students to participate in class activities in real time. However, blended synchronous learning is not without limitations. For a BSLE to be successful, critical factors that need to be considered include smooth communication between the online students and the instructor and between the online students and classroom students, the engagement of online students and the redesign of instructional activities, balanced attention to F2F students and online students, and the quality of audio. Hopefully, from this study, instructors and researchers can begin to realise the potentials and challenges with a BSLE and learn how to effectively design and implement it in practice.

\section{Acknowledgements}

This work was funded in part by the National Science Foundation of China (grant no. 61370229), the S \& T Projects of Guangdong Province (grant no. 2015A030401087, 2015B010110002, 2015B010109003, 2016B010109008), the GDUPS (2015), and Nanyang Technological University EdeX Teaching and Learning Project.

\section{References}

Altiner, C. (2015). Perceptions of undergraduate students about synchronous video conference-based English courses. Procedia - Social and Behavioral Sciences, 199, 627-633. doi:10.1016/j.sbspro.2015.07.589

Anastasiades, P. S., Filippousis, G., Karvunis, L., Siakas, S., Tomazinakis, A., Giza, P., \& Mastoraki, H. (2010). Interactive videoconferencing for collaborative learning at a distance in the school of 21st century: A case study in elementary schools in Greece. Computers \& Education, 54(2), 321-339. doi:10.1016/j.compedu.2009.08.016

Bower, M., Dalgarno, B., Kennedy, G. E., Lee, M., \& Kenney, J. (2015). Design and implementation factors in blended synchronous learning environments: outcomes from a cross-case analysis. Computers \& Education, 86, 1-17. doi:10.1016/j.compedu.2015.03.006

Bower, M. Kenney, J., Dalgarno, B., Lee, M., \& Kennedy, G. E. (2014). Patterns and principles for blended synchronous learning: Engaging remote and face-to-face learners in rich-media real-time collaborative activities. Australasian Journal of Educational Technology, 30(3), 216-272. doi:10.14742/ajet.1697

Cain, W. \& Henriksen, D. (2013). Pedagogy and situational creativity in synchronous hybrid learning: Descriptions of three models. In R. McBride \& M. Searson (Eds.), Proceedings of Society for Information Technology \& Teacher Education International Conference (pp. 291-297). Chesapeake, VA: Association for the Advancement of Computing in Education (AACE).

Cunningham, U. (2014). Teaching the disembodied: Othering and activity systems in a blended synchronous learning situation. The International Review of Research in Open and Distance Learning, 15(6). Retrieved from http://www.irrodl.org/index.php/irrodl/article/view/1793/3175

Gillies, D. (2008). Student perspectives on videoconferencing in teacher education at a distance. Distance Education, 29(1), 107-118. doi:10.1080/01587910802004878

Hastie, M., Hung, I.C., Chen, N. S., \& Kinshuk. (2010). A blended synchronous learning model for educational international collaboration. Innovations in Education and Teaching International, 47(1), 9-24. doi:10.1080/14703290903525812

Irvine, V., Code J., \& Richards L. (2013). Realigning higher education for the 21st century learner through multi-access learning. MERLOT Journal of Online Learning and Teaching, 9(2), 172-185. Retrieved from http://jolt.merlot.org/vol9no2/irvine_0613.pdf

Karal, H., Çebi, A., Turgut, Y.E. (2011). Perceptions of students who take synchronous courses through videoconferencing about distance education. TOJET: The Turkish Online Journal of Educational Technology, 10(4), 276-293. Retrieved from http://www.tojet.net/articles/v10i4/10428.pdf

Kear, K., Chetwynd, F., Williams, J., \& Donelan, H. (2012). Web conferencing for synchronous online tutorials: Perspectives of tutors using a new medium. Computers \& Education, 58, 953-963. doi:10.1016/j.compedu.2011.10.015 
Kuo, Y. C., Belland, B. R., Schroder, K. E., \& Walker, A. E. (2014). K-12 teachers' perceptions of and their satisfaction with interaction type in blended learning environments. Distance Education, 35(3), 360-381. doi:10.1080/01587919.2015.955265

Martin, M. (2005). Seeing is believing: The role of videoconferencing in distance learning British Journal of Educational Technology, 36(3), 397-405. doi:10.1111/j.1467-8535.2005.00471.x

Okita, S. Y. (2013). Educational technology and instructional design in synchronous blended learning environments. In E. J. Francois (Ed.), Transcultural blended learning and teaching in postsecondary education (pp. 170-192). Hershey, PA: Information Science Reference. doi:10.4018/978-1-4666-2014$\underline{8 . \operatorname{ch} 010}$

Rehn, N., Maor, D., \& McConney, A. (2016). Investigating teacher presence in courses using synchronous videoconferencing. Distance Education, 37(3), 302-316. doi:10.1080/01587919.2016.1232157

Stewart, A., Harlow, D., \& DeBacco, K. (2011). Students' experience of synchronous learning in distributed environments. Distance Education, 32(3), 357-381. doi:10.1080/01587919.2011.610289

Strauss, A., \& Corbin, J. (1990). Basics of qualitative research: Grounded theory procedures and techniques. Newbury Park, CA: Sage.

Szeto, E. (2015). Community of inquiry as an instructional approach: What effects of teaching, social and cognitive presences are there in blended synchronous learning and teaching? Computers \& Education, 81, 191-201. doi:10.1016/j.compedu.2014.10.015

Szeto, E., \& Cheng, A. (2016). Towards a framework of interactions in a blended synchronous learning environment: What effects are there on students' social presence experience? Interactive Learning Environments, 24(3), 487-503. doi:10.1080/10494820.2014.881391

Wang, R., \& Wiesemes, R. (2012). Enabling and supporting remote classroom teaching observation: live video conferencing uses in initial teacher education. Technology, Pedagogy and Education, 21(3), 351360. doi:10.1080/1475939X.2012.719397

Warden, C. A., Stanworth, J. O., Ren, J. B., \& Warden, A. R. (2013). Synchronous learning best practices: An action research study. Computers \& Education, 63, 197-207. doi:10.1016/j.compedu.2012.11.010

White, C. R., Ramirez, R., Smith, J. G., \& Plonowski, L. (2010). Simultaneous delivery of a face-to-face course to on-campus and remote off-campus students. TechTrends, 54(4), 34-40. doi:10.1007/s11528$\underline{010-0418-\mathrm{z}}$

Corresponding author: Changqin Huang, cqhuang@scnu.edu.cn

Australasian Journal of Educational Technology @ 2018.

Please cite as: Wang., Q. Y., Huang, C. Q., \& Quek, C. L. (2018). Students' perspectives on the design and implementation of a blended synchronous learning environment. Australasian Journal of Educational Technology, 34(1), 1-13. https://doi.org/10.14742/ajet.3404 